\title{
VOLTAMMETRIC CHARACTERIZATION OF THE BEHAVIOR OF BIOLOGICALLY ACTIVE COMPOUND ENOXIL IN VARIOUS MEDIA
}

\author{
Gheorghe Nemţoi ${ }^{1 *}$, Tudor Lupaşcu ${ }^{2}$, Alexandra Ciomaga ${ }^{1}$, Alexandru Cecal $^{1}$ \\ ${ }^{1}$ A.I.Cuza University, Faculty of Chemistry, 11-Carol 1 Bvd, 7000506- Iasi, Romania \\ ${ }^{2}$ Institute of Chemistry of ASM, 3. Academiei str, Chisinau, 2028 MD, R. Moldova \\ E-mail: nemtoi@uaic.ro,tel.+40232201334,fax.+40232201313
}

\begin{abstract}
This paper presents the results of scientific research related to the electrochemical behavior of the complex preparation, Enoxil. It was established that the oxidation-reduction process of Enoxil is quasireversible. The reactivity of Enoxil obtained from alcohol soluble enotannins is more pronounced, compared to that obtained from standard enotannins. The dependence of cathodic current intensity on Enoxil concentration is linear. This can be used to establish Enoxil concentration in solution. Cyclic voltammograms were used to establish reduction and oxidation potential and the formal redox potential on platinum electrode in sodium perchlorate aqueous environment. These features can be used for identification and determination of Enoxil in pharmaceuticals.
\end{abstract}

Keywords: complex biologically active compound Enoxil, cyclic voltammetry, standard redox potential, dosage of pharmaceuticals.

\section{Introduction}

Domestic and imported drugs are subjected to a rigorous control of their correspondence with the quality indices set out in The Analytical and Normative Documentation.

For the identification and determination of pharmaceutical substances in drugs a number of physical, physicochemical and chemical methods are currently used. The most common physical and physico - chemical methods used for identification and determination of active substance in drugs are IR spectroscopy, UV/Vis, mass spectroscopy, atomic spectroscopy, nuclear magnetic resonance spectroscopy, chromatographic methods, electrochemical methods, etc.

Enoxil is a mixture of substances of natural origin obtained at oxidation of grape seed tannins [1]. As a result of chemical oxidation processes, the breaking of polymer chain takes place in enotannins forming new compounds containing carboxyl, peroxide, alcoholic, aldehyde, ketone, ether, ester, and other functional groups. These new compounds are soluble in water and have an astringent taste. The presence of functional groups listed above has been demonstrated by acid-base titration, and spectral methods [2]. The purpose of the research presented in the current paper is to study the voltammetric behavior of Enoxil.

Electrochemical methods are commonly used in analysis of food tocopherons. Resulted tocopherylquinones give reduction polarographic waves with heights proportional to concentrations, which allows the determination of tocopherol in the initial samples [3]. The synthetic phenolic antioxidants such as Vitamin E and provitamin A can also be detected by electrochemical methods [4-6]. Due to the presence of electroactive groups in natural and synthetic oxidants molecules, the electroanalytical complex evaluation of charge transfer capabilities provides extremely valuable information on the mechanism of reactions involving these compounds in the process of preventing the degradation caused by oxidative stress [7]. Biologically active compound Enoxil exhibits significant antioxidant properties [8].

\section{Experimental}

Six types of Enoxil were taken into the study, labeled as follows:

$\mathrm{E}_{1}$ - homogenized Enoxil for Î.M. Farmaco S.A. 2009;

$\mathrm{E}_{2}$ - Enoxil homogenized on 13.XI.2009;

$\mathrm{E}_{3}$ - Enoxil from standard enotannins with $\mu \mathrm{W}, 24.03 .2010$;

$\mathrm{E}_{4}$ - Enoxil from standard enotannins without $\mu \mathrm{W}, 25.03 .2010$;

$\mathrm{E}_{5}$ - Enoxil from enotannins alcohol solution with $\mu \mathrm{W}, 24.03 .2010$;

$\mathrm{E}_{6}$ - Enoxil from enotannins alcohol solution without $\mu \mathrm{W}, 25.03 .2010$.

In $30 \mathrm{~mL}$ of solution: water $(75 \%$ vol.) - ethylic alcohol $(25 \%)$ with electrolytic background $0.1 \mathrm{M}$ tetrabutylammonium iodide (ITBA) were added $0.3 \mathrm{~mL}$ Enoxil (E1) of conc. $5 \%$ (5g Enoxil in 100ml aqueous solution), achieving a Enoxil conc. of $4.95 \times 10^{-2} \%$ in the electrochemical cell, the obtained solution being slightly turbid, evidence of precipitate formation tendency. 
The cyclic voltamogram (CV) was drawn using the working electrode (WL), platinum disc electrode (EDPt$\Phi 2 \mathrm{~mm}$ ), reference electrode, SCE (saturated calomel electrode) and the auxiliary electrode (AE), platinum wire electrode, connected to the Electrochemical Combine VoltaLab 32 (Radiometer Copenhagen) and provided with software VoltaMaster2 [9.10], the working temperature being $25^{\circ} \mathrm{C}$. As a result, was obtained a CV characteristic to quasireversible processes, shown in Figure 1. The values of potential are all determined using the SCE used as reference. In order to perform the $\mathrm{pH}$ and electroconductivity measurements, the electrochemical multimeter Consort 831 (Belgium) was used.

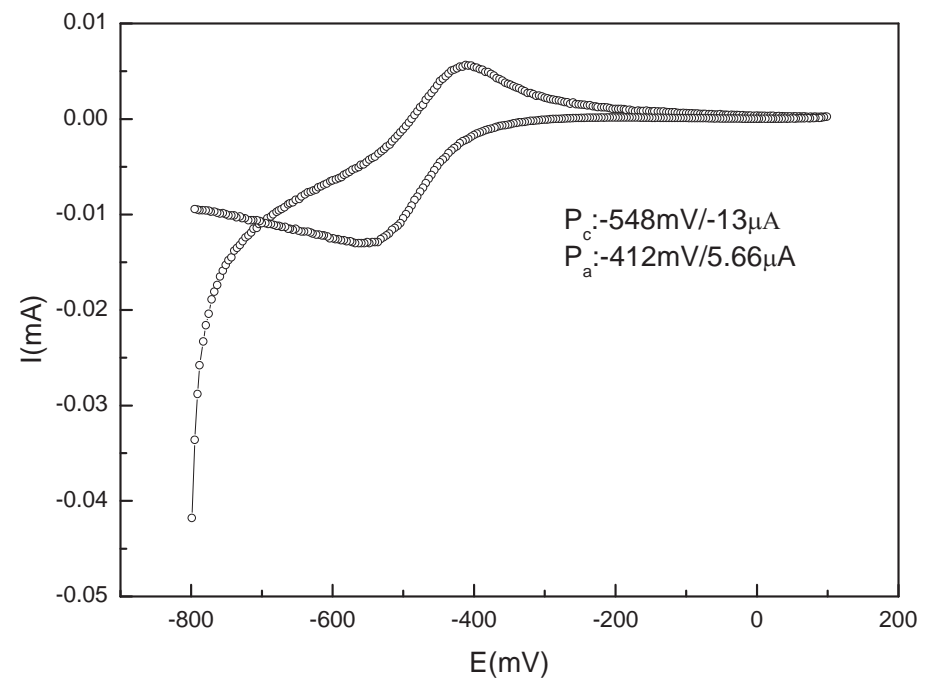

Fig. 1. Cyclic voltamogram of $E_{1}$ in ITBA at scan speed of $50 \mathrm{mV} / \mathrm{s}$

By further introducing volumes of $0.3 \mathrm{~mL}$ of $\mathrm{E} 1$, the solution becomes more opalescent, thus confirming the tendency of precipitate formation, voltammetric results obtained are presented in Table 1.

\section{Results and discussions}

Table 1

Cyclic voltammetry characteristics for $E_{1}$ in ITBA at different concentrations and scan speed of $50 \mathrm{mV} / \mathrm{s}$

\begin{tabular}{|c|c|c|c|c|c|}
\hline $\begin{array}{c}10^{2} \mathrm{c} \\
(\mathrm{g} / 100 \mathrm{~mL})\end{array}$ & $\begin{array}{c}\mathrm{E}_{\mathrm{CD}} \\
(\mathrm{mV})\end{array}$ & $\begin{array}{c}\mathrm{E}_{\mathrm{PC}} \\
(\mathrm{mV})\end{array}$ & $\begin{array}{c}\mathrm{I}_{\mathrm{PC}} \\
(\mu \mathrm{A})\end{array}$ & $\begin{array}{c}\mathrm{E}_{\mathrm{PA}} \\
(\mathrm{mV})\end{array}$ & $\begin{array}{c}\mathrm{I}_{\mathrm{PA}} \\
(\mu \mathrm{A})\end{array}$ \\
\hline 4.95 & 127 & -548 & -13.0 & -412 & 5.66 \\
\hline 9.80 & 125 & -648 & -20.4 & -388 & 4.71 \\
\hline 14.56 & 123 & -676 & -28.3 & -360 & 4.74 \\
\hline 19.23 & 120 & -723 & -34.6 & -340 & 4.19 \\
\hline 23.81 & 122 & -735 & -42.0 & -328 & 4.24 \\
\hline
\end{tabular}

The following conclusions may be drawn from table 1:

- open-circuit potential values $\left(\mathrm{E}_{\mathrm{CD}}\right)$ change very little with increasing concentration of $\mathrm{E}_{1}$, proving that no adsorption phenomena take place on the surface of EL;

- shift of the cathodic peak potential $\left(\mathrm{E}_{\mathrm{PC}}\right)$ to more negative values and of the anodic peak potential $\left(\mathrm{E}_{\mathrm{PA}}\right)$ towards more positive values, with increasing Enoxil concentration shows that complexation phenomena occur;

- in dilute $\mathrm{E}_{1}$ solution $\left(4.95 \times 10^{-2}\right), \mathrm{CV}$ shown in figure 1 highlights a quasireversible process by adding Enoxil, the anode current $\left(\mathrm{I}_{\mathrm{PA}}\right)$ decreases, but it remains practically constant at the following concentrations of $\mathrm{E}_{1}, \mathrm{CV}$ highlighting the occurrence of an irreversible process (only the cathodic process takes place) due to precipitation of the formed complex. Figure 2 shows the dependence of the cathodic current intensity on Enoxil concentration, which is linear, and the equation that can serve as standard in the given concentration range. 


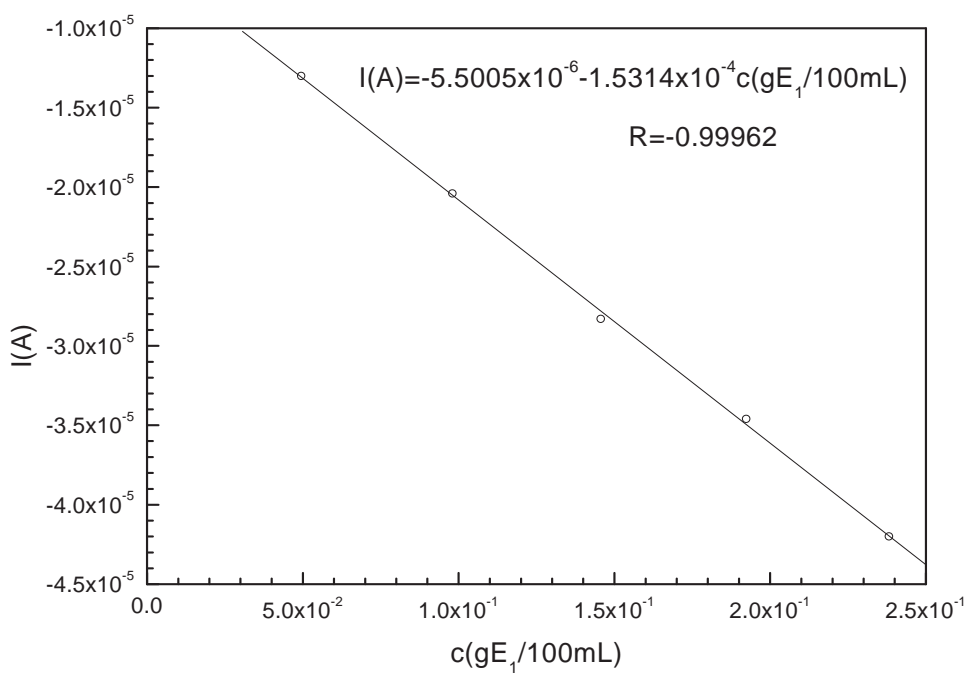

Fig. 2. Dependence of the cathodic current intensity on Enoxil concentration $\left(E_{1}\right)$ in alcohol solution of ITBA

Considering all mentioned above on the voltammetric behavior of Enoxil in alcoholic solution of tetrabutylammonium iodide on platinum electrode, its determination on the basis of the cathodic process can be recommended, using the calibration graph (Fig. 2).

On acidification of solution with $\mathrm{HClO}_{4}$ at a $\mathrm{pH}$ below 2.6, no cathodic peak can be revealed (there is a continuous decrease of cathode current), hazing of the solution is more obvious due to the formation of a yellowish precipitate. By alkalinization of the solution with $\mathrm{NaOH}$ to $\mathrm{pH} 8.8$ the precipitate darkens, yellow flakes are present, and the CV doesn't present any peaks. The electroreduction process evidenced for the considered above system, may be due to the presence of peroxide group in Enoxil, which is reduced, process facilitated by the presence of iodide ion in the electrolytic background.

In order to avoid the influence of the electrolytic background, we will consider an aqueous solution $0.1 \mathrm{M}$ of $\mathrm{NaClO}_{4}$ with $\mathrm{pH}=5.5$ and electronegativity $10.78 \mathrm{mS} / \mathrm{cm}$ and using VoltaLab32 we will draw the $\mathrm{CV}$ in the range $-800 \div 1200 \div-800$ with a scan speed of $50 \mathrm{mV} / \mathrm{s}$.

The solutions with 5\% (5g Enoxil/100mL solution) were prepared of each type of Enoxil, of which were taken volumes of $0.3 \mathrm{~mL}$ or $1.0 \mathrm{~mL}$ (at the end for the last addition) that were added to $30 \mathrm{~mL} 0.1 \mathrm{M}$ solution $\mathrm{NaClO}_{4}$ and $\mathrm{CV}$ were drawn, at working temperature of $25^{\circ} \mathrm{C}$. Removing oxygen from the solution was achieved by bubbling nitrogen for 5 minutes before plotting the voltamogram. Figure 3 presents the $\mathrm{CV}$ obtained for the most diluted solutions of Enoxil $\left(4.95 \times 10^{-2} \%\right)$ and Figure 4 - the 6 types of Enoxil of conc. $19.23 \times 10^{-20} \%$.

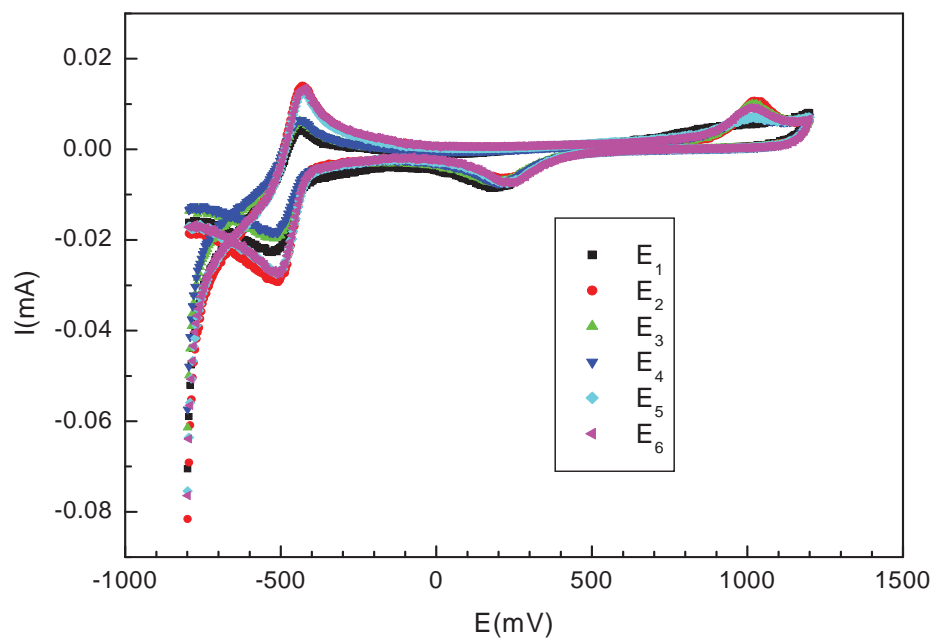

Fig. 3.CV of the 6 types of Enoxil at $4.95 \times 10^{-2} \%$ in $0.1 \mathrm{M} \mathrm{NaClO}$ at a scan speed of $50 \mathrm{mV} / \mathrm{s}$ 
Figure 3 shows that overlapping peaks found in the positive range of potentials can be attributed to electrolytic background, while in the negative range of potentials, the anodic peak coupled with the cathodic one, reveals a quasireversible redox process characteristic to Enoxil. The variation in peak intensities of the anodic processes $\left(\mathrm{I}_{\mathrm{PA}}\right)$ is different from the cathodic ones $\left(\mathrm{I}_{\mathrm{PC}}\right)$ and can be grouped as follows:

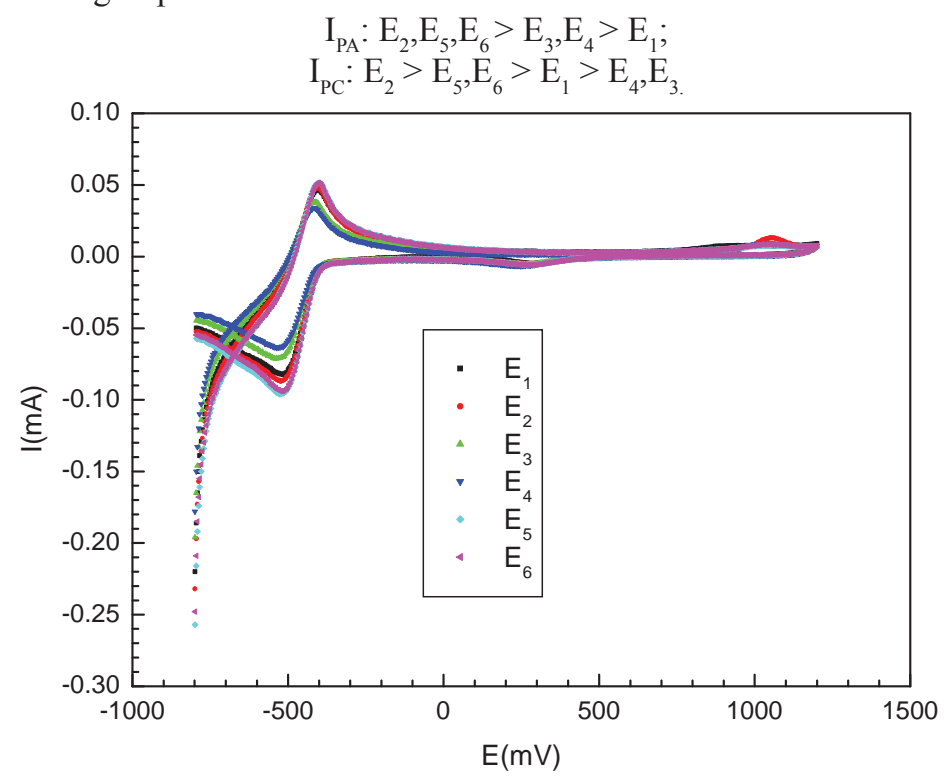

Fig. 4. CV of the 6 types of Enoxil at $19.23 \times 10^{-2} \%$ in $0.1 \mathrm{M} \mathrm{NaClO}$ at a scan speed of $50 \mathrm{mV} / \mathrm{s}$

$\mathrm{CV}$ in figure 4 confirms the existence of peaks in the positive range of potentials due to the medium, and for that reason in figure 5, we will present for $\mathrm{E}_{1}$, the $\mathrm{CVs}$ both for expanded and restricted ranges, where only Enoxil characteristic peaks occur. The reproducibility is very good, given by the overlapping peaks.

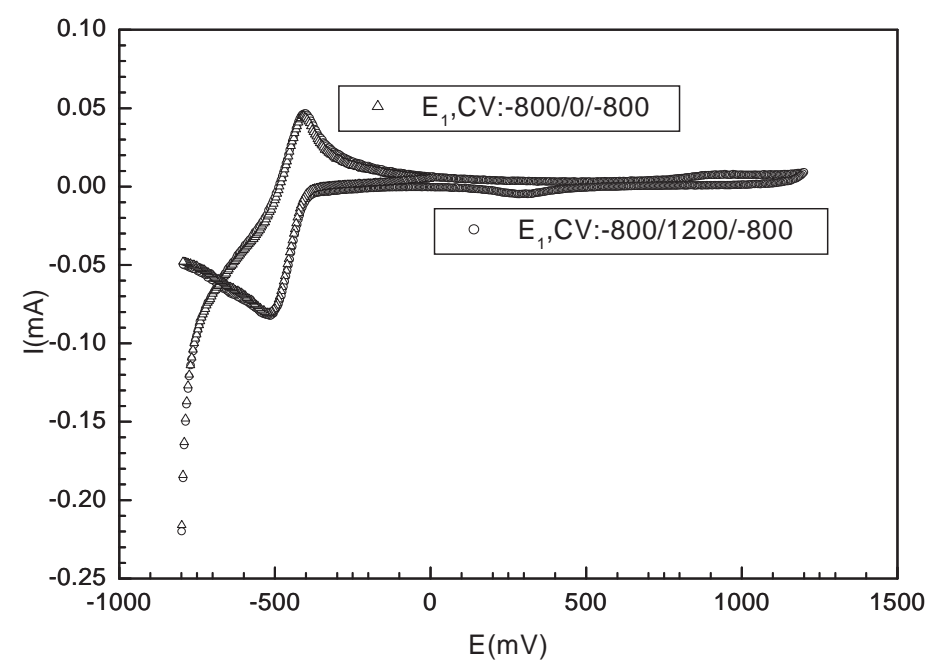

Fig. 5.CV of $E_{1}$ at a concentration of $19.23 \times 10^{-2} \%$ in $0.1 \mathrm{M} \mathrm{NaClO}$ at a scan speed of $50 \mathrm{mV} / \mathrm{s}$ for expanded and restricted ranges

Considering the variation of peak current intensity for Enoxil concentration $19.23 \times 10^{-2} \%$, the 6 types of Enoxil may be grouped as follows:

$$
\begin{gathered}
\mathrm{I}_{\mathrm{PA}}: \mathrm{E}_{5} \mathrm{E}_{2}, \mathrm{E}_{6}>\mathrm{E}_{3}, \mathrm{E}_{4}, \mathrm{E}_{1} ; \\
\mathrm{I}_{\mathrm{PC}}: \mathrm{E}_{5}, \mathrm{E}_{6}>\mathrm{E}_{2}>\mathrm{E}_{1}>\mathrm{E}_{3}, \mathrm{E}_{4} .
\end{gathered}
$$

There is a slight modification as compared to the Enoxil more diluted solution, but considering that the peak current intensity is directly proportional to the velocity of the redox process, it may be concluded that Enoxil samples $\mathrm{E}_{5}$ and $\mathrm{E}_{6}$ are the most reactive, while the $\mathrm{E}_{4}$ sample is the least reactive. Table 2 presents the collected data obtained by cyclic voltammetry at a scan speed of $50 \mathrm{mV} / \mathrm{s}$ for the 6 types of Enoxil on platinum disk electrode in $0.1 \mathrm{M} \mathrm{NaClO}_{4}$ solution. $_{\text {. }}$ 
Solutions parameters and peak characteristics of $\mathrm{CVs}$

Table 2

For aqueous solutions of $0.1 \mathrm{M} \mathrm{NaClO} \mathrm{N}_{4}$ of the 6 types of Enoxil

\begin{tabular}{|c|c|c|c|c|c|c|}
\hline $\begin{array}{c}10^{2} \mathrm{c} \\
(\mathrm{g} / 100 \mathrm{~mL})\end{array}$ & $\mathrm{pH}$ & $\begin{array}{c}\kappa \\
\mathrm{mS} / \mathrm{cm}\end{array}$ & $\begin{array}{l}-\mathrm{E}_{\mathrm{PC}} \\
(\mathrm{mV})\end{array}$ & $\begin{array}{c}-\mathrm{I}_{\mathrm{PC}} \\
(\mu \mathrm{A})\end{array}$ & $\begin{array}{c}-\mathrm{E}_{\mathrm{PA}} \\
(\mathrm{mV})\end{array}$ & $\begin{array}{c}\mathrm{I}_{\mathrm{PA}} \\
(\mu \mathrm{A})\end{array}$ \\
\hline \multicolumn{7}{|c|}{$E_{1}$} \\
\hline 4.95 & 2.94 & 11.10 & 523 & 22.2 & 431 & 6.85 \\
\hline 9.80 & 2.71 & 11.30 & 516 & 45.8 & 420 & 25.0 \\
\hline 14.56 & 2.58 & 11.48 & 511 & 65.4 & 412 & 37.0 \\
\hline 19.23 & 2.49 & 11.69 & 524 & 88.0 & 408 & 45.1 \\
\hline 34.16 & 2.32 & 12.05 & 528 & 132.0 & 392 & 62.8 \\
\hline \multicolumn{7}{|c|}{$\begin{array}{c}I_{P C}(\mu A)=5.3208-570.75823 c+492.24991 c^{2} ; R=0.99898 \\
I_{P A}(\mu A)=-10.91388+405.99054 c-558.70508 c^{2} ; R=0.99685\end{array}$} \\
\hline \multicolumn{7}{|c|}{$\mathrm{E}_{2}$} \\
\hline 4.95 & 2.88 & 11.07 & 508 & 29.3 & 431 & 14.0 \\
\hline 9.80 & 2.71 & 11.34 & 512 & 48.2 & 424 & 28.1 \\
\hline 14.56 & 2.59 & 11.52 & 524 & 68.0 & 415 & 38.3 \\
\hline 19.23 & 2.49 & 11.72 & 524 & 87.2 & 408 & 48.1 \\
\hline 38.46 & 2.28 & 12.25 & 536 & 155.0 & 388 & 82.8 \\
\hline \multicolumn{7}{|c|}{$\begin{array}{c}I_{P C}(\mu A)=-7.36359-4.39348 c+0.01437 c^{2} ; R=0.99984 \\
I_{P A}(\mu A)=1.09012+2.82228 c-0.01819 c^{2} ; R=0.9993\end{array}$} \\
\hline \multicolumn{7}{|c|}{$\mathrm{E}_{3}$} \\
\hline 4.95 & 3.02 & 11.14 & 523 & 19.7 & 439 & 6.32 \\
\hline 9.80 & 2.80 & 11.28 & 512 & 40.9 & 420 & 22.8 \\
\hline 14.56 & 2.68 & 11.43 & 528 & 57.0 & 420 & 31.8 \\
\hline 19.23 & 2.61 & 11.52 & 540 & 71.2 & 412 & 38.2 \\
\hline 34.16 & 2.46 & 11.77 & 540 & 112.0 & 404 & 60.3 \\
\hline \multicolumn{7}{|c|}{$\begin{array}{c}I_{P C}(\mu A)=0.54852-441.465 c+329.27349 c^{2} ; R=0.99928 \\
I_{P A}(\mu A)=-6.44928+304.78515 c-323.07386 c^{2} ; R=0.99167\end{array}$} \\
\hline \multicolumn{7}{|c|}{$\mathrm{E}_{4}$} \\
\hline 4.95 & 3.04 & 10.88 & 511 & 18.5 & 432 & 6.5 \\
\hline 9.80 & 2.84 & 10.90 & 516 & 34.5 & 428 & 16.4 \\
\hline 14.56 & 2.72 & 10.91 & 519 & 49.2 & 420 & 25.2 \\
\hline 19.23 & 2.64 & 11.03 & 536 & 63.7 & 416 & 34.0 \\
\hline 34.16 & 2.48 & 11.14 & 559 & 102 & 408 & 55.8 \\
\hline \multicolumn{7}{|c|}{$\begin{array}{c}\mathrm{I}_{\mathrm{PC}}(\mu \mathrm{A})=-0.97988-361.38485 \mathrm{c}+191.8709 \mathrm{c}^{2} ; \mathrm{R}=0.99994 \\
\mathrm{I}_{\mathrm{PA}}(\mu \mathrm{A})=-4.44+227.15128 \mathrm{c}-148.47841 \mathrm{c}^{2} ; \mathrm{R}=0.9999\end{array}$} \\
\hline \multicolumn{7}{|c|}{$\mathrm{E}_{5}$} \\
\hline 4.95 & 2.86 & 11.16 & 516 & 27.5 & 428 & 12.8 \\
\hline 9.80 & 2.63 & 11.32 & 512 & 52.5 & 416 & 27.7 \\
\hline 14.56 & 2.51 & 11.50 & 508 & 74.1 & 408 & 40.1 \\
\hline 19.23 & 2.41 & 11.85 & 528 & 96.2 & 404 & 51.5 \\
\hline 34.16 & 2.24 & 12.28 & 527 & 151 & 395 & 61.7 \\
\hline \multicolumn{7}{|c|}{$\begin{array}{c}I_{P C}(\mu A)=-0.3855-564.72738 c+361.95061 c^{2} ; R=0.99987 \\
I_{P A}(\mu A)=-7.13662+425.25416 c-653.75472 c^{2} ; R=0.99844\end{array}$} \\
\hline \multicolumn{7}{|c|}{$\mathrm{E}_{6}$} \\
\hline 4.95 & 2.85 & 11.06 & 516 & 27.6 & 424 & 13.5 \\
\hline 9.80 & 2.63 & 11.26 & 516 & 52.8 & 412 & 29.8 \\
\hline 14.56 & 2.50 & 11.46 & 516 & 73.5 & 412 & 41.1 \\
\hline 19.23 & 2.41 & 11.61 & 524 & 94.1 & 400 & 51.4 \\
\hline 34.16 & 2.25 & 12.09 & 532 & 148.0 & 388 & 71.6 \\
\hline \multicolumn{7}{|c|}{$\begin{array}{l}I_{P C}(\mu A)=-1.65877-548.01533 c+350.42436 c^{2} ; R=0.99988 \\
I_{P A}(\mu A)=-3.38475+372.85301 c-449.51928 c^{2} ; R=0.99932\end{array}$} \\
\hline
\end{tabular}


Table 2 shows that increasing concentration of Enoxil in the electrochemical cell where the electrolytic background is sodium perchlorate, leads to a decrease in $\mathrm{pH}$ accompanied by a slight increase in electroconductivity ( $\kappa$ ), which can be attributed to hydrogen ions generated by Enoxil during dissolution. For every type of Enoxil, the dependency of peak current upon concentration was established, for both the anodic $\left(\mathrm{I}_{\mathrm{PA}}(\mu \mathrm{A})\right)$ and cathodic $\left(\mathrm{I}_{\mathrm{PC}}(\mu \mathrm{A})\right)$ processes. Also, the corresponding correlation coefficients $(\mathrm{R})$ are given, with values very close to unity, by 2 nd order polynomial fitting of experimental data.

Table 3 presents the mean values of reduction potentials $\left(\mathrm{E}_{\mathrm{PC}}\right)$ and oxidation potentials $\left(\mathrm{E}_{\mathrm{PA}}\right)$ as well as a formal redox potential $\left(\mathrm{E}^{0}\right)$ calculated according to the formula:

$$
\mathrm{E}^{0^{\prime}}=\frac{\mathrm{E}_{\mathrm{PC}}+\mathrm{E}_{\mathrm{PA}}}{2}
$$

Table 3

The mean values of reduction and oxidation potentials, as well as Enoxil formal redox potential on platinum electrode in aqueous solution of $0.1 \mathrm{MNaClO}_{4}$

\begin{tabular}{|c|c|c|c|}
\hline Enoxil & $\begin{array}{c}-\mathrm{E}_{\mathrm{PC}} \\
\mathrm{mV}\end{array}$ & $\begin{array}{c}-\mathrm{E}_{\mathrm{PA}} \\
\mathrm{mV}\end{array}$ & $\begin{array}{c}-\mathrm{E}^{0^{\prime}} \\
\mathrm{mV}\end{array}$ \\
\hline $\mathrm{E}_{1}$ & 520.4 & 412.6 & 466.5 \\
\hline $\mathrm{E}_{2}$ & 520.8 & 413.2 & 467.0 \\
\hline $\mathrm{E}_{3}$ & 528.6 & 419.0 & 473.8 \\
\hline $\mathrm{E}_{4}$ & 528.2 & 420.8 & 474.5 \\
\hline $\mathrm{E}_{5}$ & 518.2 & 410.2 & 464.2 \\
\hline $\mathrm{E}_{6}$ & 520.8 & 407.2 & 464.0 \\
\hline
\end{tabular}

The close values of each of the three forms of potential shown in Figure 3, prove that regardless of the type of Enoxil, the electrochemically reactive group of Enoxil is characterized by a reduction potential $\overline{\mathrm{E}}_{\mathrm{PC}}=-522.8 \mathrm{mV}$ and an oxidation potential $\overline{\mathrm{E}}_{\mathrm{PA}}=-413.8 \mathrm{mV}$ and the formal redox potential of this group will be $\overline{\mathrm{E}}^{0^{\prime}}=-468.3 \mathrm{mV}$. These values should be qualitative indicators of Enoxil presence and the intensity of the peak current will provide quantitative estimates for a subsequent dosing of Enoxil by voltammetry.

By acidifying the solution with $\mathrm{HClO}_{4}$ gives a marked rise in cathode current (increased speed of the reduction process) and anodic peak flattening, as shown for $\mathrm{E}_{4}$ in figure 6 .

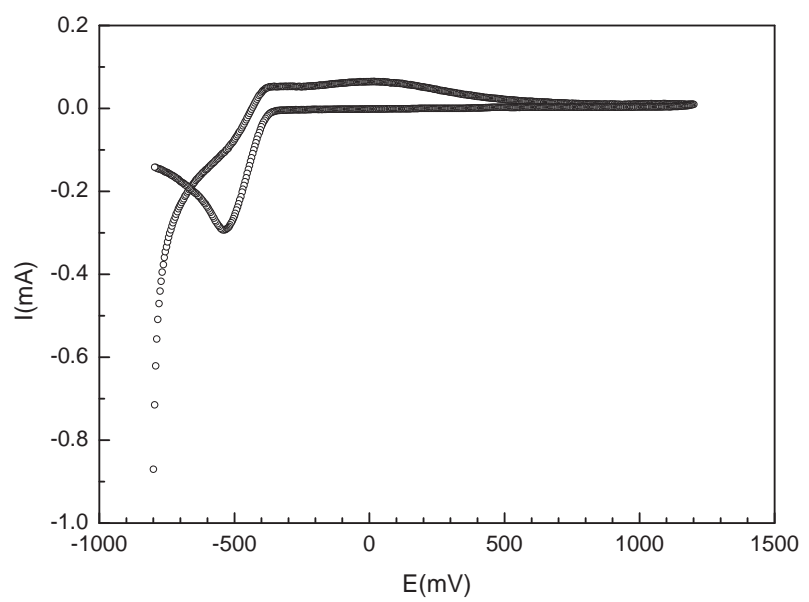

Fig. 6. $\mathrm{CV}$ at $\mathrm{pH}=1.86$ for the solution of $34.16 \times 10^{-2} \% \mathrm{E}_{4}$ in $0.1 \mathrm{M} \mathrm{NaClO}$ at a scan speed of $50 \mathrm{mV} / \mathrm{s}$

By alkalinization of Enoxil solution leads to the decrease of peak intensities and even at a slightly alkaline $\mathrm{pH}$, the peaks characteristic to Enoxil presence practically disappear, as illustrated in Figure 7 for $\mathrm{E}_{4}$. 


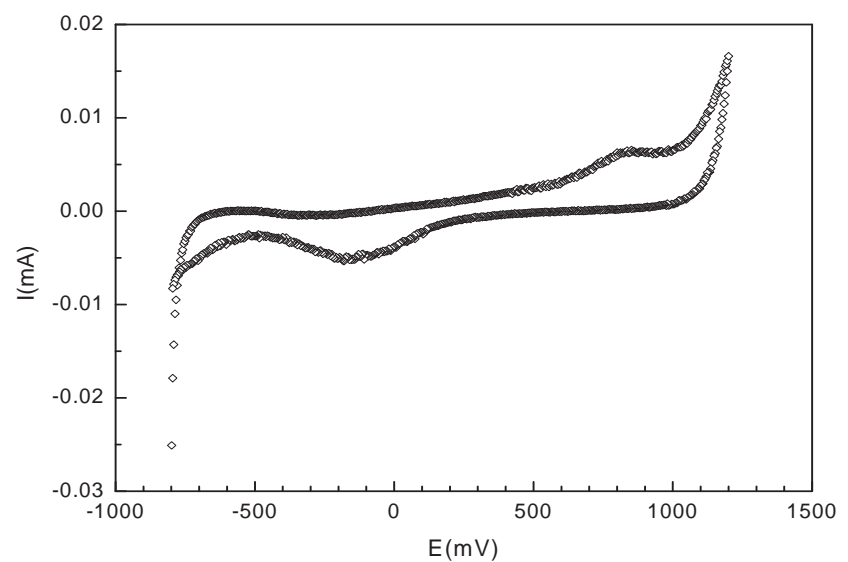

Fig. 7.CV at $\mathrm{pH}=7.46$ for the solution of $34.16 \times 10^{-2} \% \mathrm{E}_{4}$ in $0.1 \mathrm{M} \mathrm{NaClO}$ at scan speed of $50 \mathrm{mV} / \mathrm{s}$.

After the voltammetric measurements were performed in $0.1 \mathrm{M} \mathrm{NaClO}_{4}$ solution on platinum electrode, as shown in Table 2, $\mathrm{pH}$ values are functions of Enoxil concentration, acidification or alkalinization of the solution leading to changes in $\mathrm{CV}$ and even annihilation of Enoxil electroreactivity.

This study allows us to conclude that hydrosoluble Enoxil can be studied by voltammetry in aqueous sodium perchlorate medium as electrolytic background on platinum electrode by highlighting a quasireversible redox process.

\section{Conclusions}

- The dependence of cathodic current intensity of Enoxil concentration is linear. This can be used to determine the concentration of Enoxil in unknown solutions.

- The analysis of cyclic voltammograms reveals a quasireversible redox process characteristic to Enoxil.

- The Enoxil samples obtained from alcohol soluble enotannins are more reactive over time, compared with enoxil obtained from standard enotannins.

- The analysis of reduction and oxidation potentials and of the formal redox potential of Enoxil samples allows us to estimate these values, which may serve as qualitative indices of Enoxil preparation that can be used for its determination by voltammetry.

\section{References}

[1]. Duca Gh., Lupaşcu T., Vlad P., Kulciţki V., Nastas R. Studies on the water solubilization processes of oenotanins and their physico-chemical properties. Chemistry Journal of Moldova. 2006, 1 (1), P. 74-79.

[2]. Lupaşcu T., Duca Gh., Giurgincă M., Vlad P. et. Natural compounds with antioxidant propertes. Key Engeenering Materials, 2009, V. 415, P.P.25-28.

[3]. Wisser K., Heimann W., Fritsche C., Fresenius Z. Anal. Chem., 1967, 230, 189.

[4]. Ruiz M.A., Yanez-Sedeno Poloma, Pingaron J.M., Electroanalysis 1994, 6, 475.

[5]. Ishar M.P.S., Kaur R., Kaur G., Gandhi R.P., Indian J. Chem, 1996, 35B, 641.

[6]. Surez - Fernendaz A.L., Alaines-Varela G, Costa-Garcea A., Electrochimica Acta, 1999, 44, 4489.

[7]. Liteanu S., G.L. Radu. Elemente de bio-electroanaliză a unor principii active antioxidante. Editura Printech, Bucureşti, 2005, 232 p.

[8]. Brevet de Invenție. 3979 MD F 1. Compus cu proprietăți antioxidante. Lupaşcu T., Duca Gh., Lupaşcu L., Giurgincă M., Meghea A. BOPY, nr. 11/2009.

[9]. Nemtoi Gheorghe, Ionica Florica, Lupascu Tudor and Cecal Alexandru,Voltammetric characterirization of the iron behaviour from steels in different electrolytic media, Chemistry Journal of Moldova. General,Industrial and Ecological Chemistry, 5,(1), 2010, 98-105

[10]. Mareci D., Bocanu C., Nemtoi Gh. and Aelenei Delia, Electrochemical behaviour of titanium alloys in artificial saliva, J.Serb.Chem.Soc., 70, 2005, 891-897, 